\title{
Prediction and Measurement of the Bending Strength of the RCC
}

\author{
Mustapha Zdiri, ${ }^{1,2)}$ Mongi Ben Ouezdou, ${ }^{1)}$ Nor-edine Abriak, ${ }^{3)}$ and Jamel Neji
}

(Received June 12, 2008, Revised March 30, 2009, Accepted April 30, 2009)

\begin{abstract}
The present work deals with the prediction, through models and experimental evaluation, of the bending strength of roller compacted concrete (RCC) for pavement applications. This concrete was manufactured using low cement proportioning (150 to $250 \mathrm{~kg} / \mathrm{m}^{3}$ ). The characterization of hardened RCC was carried out by experimental measurements of bending strengths. The predictions of these characteristics were achieved using empirical models. Comparison, of the values found in experiments with those empirically obtained, was made in order to choose and to propose the adapted and the most reliable models of prediction. The study showed that the bending strengths of the RCC mixture, experimentally found, can be also identified by models.
\end{abstract}

Keywords: roller compacted concrete (RCC), bending strength, models, prediction, tests.

\section{Introduction}

Roller compacted concrete (RCC) is a composite material made up of a matrix which is the hardened cement paste and of inclusions representing the aggregates. After hardening, the matrix forms a porous structure, containing interstitial and free water (according to pores dimension). Aggregates such as gravel, sand and fine elements are inert and have an elastic behavior. Furthermore, RCC used in pavement, supports forces and consequently stresses which involve deformations and reciprocally. The mechanical characterization and the knowledge of this material resistance represent a major importance for the structural design of rigid pavements.

Similar for conventional concrete (CC) mixtures, the RCC properties in a hardened state depend on many parameters such as the nature and quantity of the cement matrix, the water/ cement ratio as well as the aggregates quality. Moreover, the RCC properties in a hardened state are particularly influenced by compaction quality. ${ }^{1}$ The $\mathrm{CC}$ mechanical behavior, under mechanical loading, was the subject of many studies. However, only a limited number of studies relative to the mechanical strengths of the RCC were found.

Gauthier et al. ${ }^{2}$ carried out studies on RCC mixtures of cement dosages ranging between 12 and $16 \%$ of the dry components. They showed in their studies that the properties of the cement

\footnotetext{
${ }^{1)}$ Civil Engineering Laboratory, National Engineering School of Tunis, Tunis-Belvédère 1002, Tunisia. E-mail: zdiri_ms@yahoo.fr ${ }^{2)}$ Laboratoire LAMTI-Universite d'Artois-Technoparc Futura 62400 Béthune - France.

${ }^{3)}$ Labo de Génie Civil Environnemental - Ecole des Mines de Douai, rue Charles Boursel B.P838-59508 France.

${ }^{4)}$ Applied Mechanics and Systems Research Laboratary Polytechnic school of Tunis, Tunisia.

Copyright (c) 2009, Korea Concrete Institute. All rights reserved, including the making of copies without the written permission of the copyright proprietors.
}

matrix and granular inclusions explain the high mechanical strengths of the RCC mixtures. The low cement dosage of these mixtures produces a very low porous cementing matrix giving an improved behavior and high resistances. ${ }^{2}$

Ouellet et al. ${ }^{3}$ proved in their experimental studies that the mechanical characteristics of the RCC are also influenced by the properties of the two phases composing the mixture, which are the hydrated cement paste and the aggregates.

For the prediction of bending strength, the American Concrete Institute $(\mathrm{ACI})^{4}$ and Ouellet et al., ${ }^{3}$ defined empirical models for concrete simulations which were validated by experimental tests on pastes, mortars and CC.

In this study, ACI and Ouellet models were adopted for the prediction of bending strength of the RCC mixtures for pavements. This study will include, also, the realization of experimental 3point bending tests on prismatic specimens. These specimens were made according to the method of French National Project BaCaRa. ${ }^{5,6}$ Low cement proportioning ranging between 150 and $250 \mathrm{~kg} / \mathrm{m}^{3}$, was chosen for economic reasons representing a proportion ranging between 5 and $11.5 \%$ of the dry components. Comparisons will, consequently, be realized between empirical and experimental results and an empiric low was proposed for the prediction of the bending strength of the RCC.

\section{Experimental tests of bending strength}

The measurement of mechanical strengths of RCC specimens was carried out in accordance with the standards requirements (European EN $12390-5^{7}$ and ASTM C 293-02 ${ }^{8}$ ). The cast procedure of RCC specimens, described and intended for strength tests, was followed. In this experimental work, it was operated at constant loading speed. The objective was the studying of RCC bending strengths.

\subsection{Materials used}

The used binder is a hydraulic Portland cement, which repre- 
sents the permanent element for RCC manufacture. In the current study, the cement used CEM II/C-L 32.5 came from the K. cement factory (north of Tunisia) and had a relative density equal to $3,029 \mathrm{~kg} / \mathrm{m}^{3}$. In this work, it was impossible to use additions such as fly ash, slag, silica fume and pozzolan because they are not available in Tunisia (and are expensive to import). Moreover, different classes of aggregate are necessary to fill the interaggregate space to the maximum extent. Two aggregate types were used: rolled for the siliceous sands and crushed for the limestone sands, and gravels. ${ }^{6}$ Characteristics and data relative to these aggregates are presented in Table 1.

\subsection{Preparation of the RCC mixtures}

In RCC formulation, the dosage of the various proportions of dry materials aims to the obtaining of higher strengths of these mixtures. To determine the components percentages, the compressible packing model (CPM) was applied by the use of the software "Rene LCPC.", 910 It allowed RCC mixtures to be produced with minimal porosity giving an optimal compactness. It describes the compressive strength of hardened concretes using Portland cement. To increase compactness and to reduce the porosity of the granular skeleton of RCC, this model was applied while varying the mixtures components and by fixing three cement proportioning. Results of the 8 mixtures are summarized in Table 2.

\subsection{Three point bending test on prismatic specimens of RCC}

The bending strength of RCC is important in the design phase of pavement slab. The evaluation of the bending strength of RCC specimen consists in measuring, under loads effect, the maximum strength reached at the specimen base. In this test, an RCC prism of $(7 \mathrm{~cm} \times 7 \mathrm{~cm} \times 28 \mathrm{~cm})$ was subjected to a bending stress by application, until load failure, in the mid-span. The maximum theoretical tensile strength reached on bottom fiber of the prism corresponds to the failure modulus. ${ }^{1}$

\subsubsection{Set-up method of prismatic RCC specimens $(7 \times$ $7 \times 28$ )}

The cast procedures of RCC specimens, for 3-point bending tests, were completely different from those usually employed for the CC. ${ }^{1}$ The vibro-compaction technique was developed for the set-up of prismatic specimens $7 \times 7 \times 28$ (bending strength) (Fig. 1). This method was used and described in the French

Table 1 Characteristics of aggregates.

\begin{tabular}{l|l|l|c|c|c}
\hline Aggregates & \multicolumn{1}{|c|}{ Type } & Source & Relative density $(\rho)\left(\mathrm{kg} / \mathrm{m}^{3}\right)$ & Los Angeles & Flatting ratio $(\%)$ \\
\hline \hline Sand Kh & Rolled sand 0/5 & Khlidia $^{(1)}$ & 2,575 & - & - \\
\hline Sand JO & Crashed sand 0/5 & Djebel Ouest $^{(1)}$ & 2,530 & - & - \\
\hline Gravel 4/16 & Crashed gravel 4/16 & Djebel El-Ressas $^{(1)}$ & 2,650 & 28.30 & 19.37 \\
\hline Gravel 0/20 & Crashed gravel 0/20 & Djebel El-Ressas $^{(1)}$ & 2,631 & 26.50 & 25.58 \\
\hline
\end{tabular}

${ }^{(1)}$ Area in the North of Tunisia.

Table 2 Constituents of the used aggregates for the RCC mixtures (\%) - case of proportioning $250 \mathrm{~kg} / \mathrm{m}^{3}$.

\begin{tabular}{c|l|c|c|c|c|c|c}
\hline No & Mixture & Cemstituent & Sand Kh & Sand JO & Gravel 4/8 & Gravel 0/20 & Gravel 4/16 \\
\hline \hline M1 & Sand Kh and Gravel 0/20 & 11.22 & 26.63 & - & - & 62.13 & - \\
\hline M2 & Sand Kh, Sand JO and Gravel 0/20 & 11.22 & 18 & 17.51 & - & 53.26 & - \\
\hline M3 & Sand Kh, Sand JO, Gravel 4/8 and Gravel 0/20 & 11.22 & 17.89 & 14 & 12.50 & 44.39 & - \\
\hline M4 & Sand JO and Gravel 0/20 & 11.22 & & 26.63 & - & 62.15 & - \\
\hline M5 & Sand Kh, Sand JO and Gravel 4/16 & 11.22 & 22.50 & 21.91 & - & - & 44.41 \\
\hline M6 & Sand Kh and Gravel 4/16, & 11.22 & 35.53 & & - & - & 53.29 \\
\hline M7 & Sand Kh, Sand JO, Gravel 4/8 and Gravel 4/16 & 11.22 & 21.50 & 17.40 & 14.40 & - & 35.54 \\
\hline M8 & Sand Kh and Gravel 4/8 & 11.22 & 44.41 & - & 44.41 & - & - \\
\hline
\end{tabular}

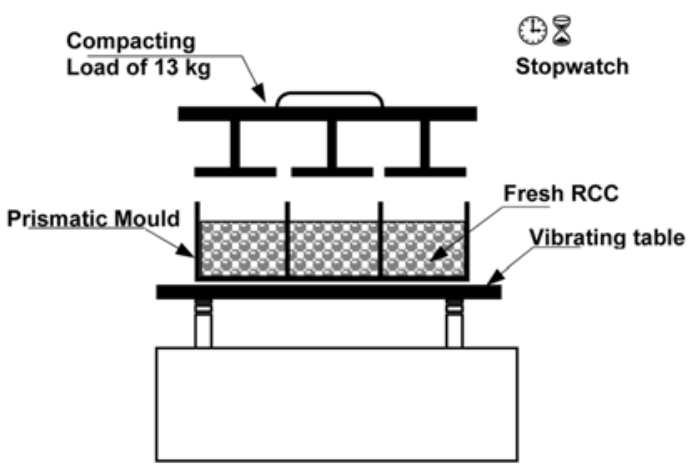

(a)

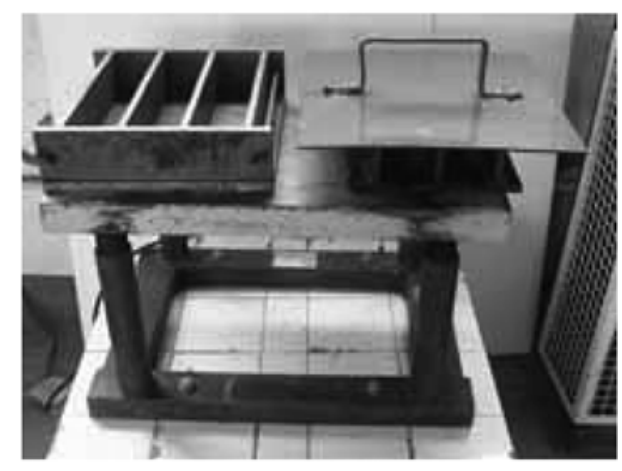

(b)

Fig. 1 (a) and (b) mould and load conceived for the set-up of the prismatic RCC specimens $(7 \times 7 \times 28)$. 
National Project BaCaRa. ${ }^{5}$ To prepare the necessary specimens for RCC strength for the 3-point bending test, special mould was prepared by the development of vibro-compaction technique. It consisted in consolidating the fresh RCC by suitable compaction in steel moulds using a vibrating table and an applied load (Fig. 1).

\subsubsection{Test schedule}

After the specimens cast according to the BaCaRa method, ${ }^{5,6}$ they were stored in water at a temperature of about $20^{\circ} \mathrm{C}$ and relative humidity more than $95 \%{ }^{6}$. The prisms were normally put at test on the perpendicular side compared to their set-up position. It was recommended to prepare three specimens per expiry. ${ }^{11}$ In this 3-point bending test, failure occurred when the capacity of tensile strength of RCC in bottom fiber, immediately under the loading point, was reached (Fig. 2).

\section{Predictions of the RCC bending strengths through models}

\subsection{Mechanicals characteristics of the RCC}

Bending strength called also failure modulus of the RCC is one among the parameters to be taken into account in the design of RCC pavement as for any other rigid concrete pavement. The fatigue criterion was determined by the bending strength of concrete, corresponding to cracking control in the RCC slab. ${ }^{1}$ Furthermore, bending strengths represent the main elements for the design and the analysis of RCC pavement structures. ${ }^{11}$

In this section, empirical models were applied which describe the bending strengths (at 28 days) of hardened concretes using Portland cement. These models take into account the characteristic strength of cement, the cement concentration in paste, the adhesion between paste and aggregates and the intrinsic strength of the rock. ${ }^{9}$ The used RCC mixtures were characterized by low cement content and therefore the paste volume covering aggregates was relatively low. Compact granular skeleton should necessarily support the applied stresses and should contribute strongly to the mechanical strength of RCC. ${ }^{6}$

\subsection{Prediction of the bending strength}

The Eq. (1), suggested by ACI, ${ }^{4}$ was applied for the prediction of the bending strength of RCC $F_{f}$ based on the compressive strength $F_{c}$.

$$
F_{f}=0.6 \sqrt{F_{c}}
$$

In this research work, model suggested by Ouellet ${ }^{3}$ was also used through the empirical Eq. (2) between compressive and bending strengths of the RCC at 28 days ${ }^{1,3}$ :

$$
F_{f}=\left(F_{c}\right)^{0.459}
$$

The results of the two models for three cement proportioning

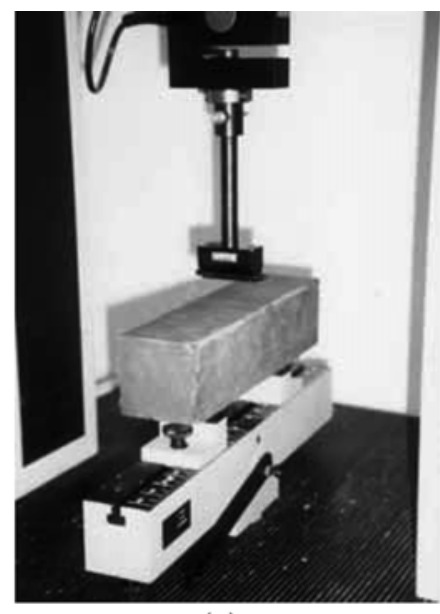

(a)

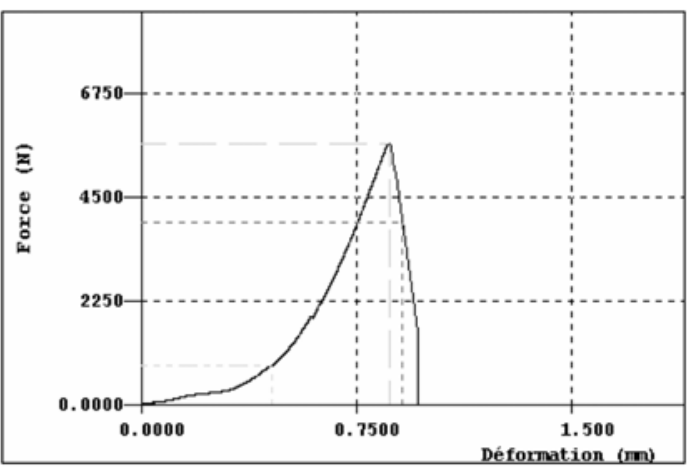

(b)

Fig. 2 (a) Loading in mid-span of RCC specimen, (b) Bending strength curve under loading.

Table 3 Bending strength for the 8 studied mixtures of RCC by the models - proportioning $150 \mathrm{~kg} / \mathrm{m}^{3}$.

\begin{tabular}{l|c|c|c|c|c|c|c|c}
\hline Cement proportioning 150 kg Mixture & M1 & M2 & \multirow{2}{*}{ M3 } & \multirow{2}{*}{ M4 } & \multirow{2}{*}{ M5 } & \multirow{2}{*}{ M6 } & \multirow{2}{*}{ M7 } & \multirow{2}{*}{ M8 } \\
\hline \hline Compressive strength of the RCC Fc $(\mathrm{MPa})$ & 5.353 & 5.203 & 5.198 & 5.841 & 6.198 & 6.239 & 7.092 & 6.908 \\
\hline Bending strength $\mathrm{F}_{f}(\mathrm{MPa})(\mathrm{ACI})$ & 1.388 & 1.369 & 1.368 & 1.450 & 1.494 & 1.499 & 1.598 & 1.577 \\
\hline Bending strength $\mathrm{F}_{f}(\mathrm{MPa})(\mathrm{Ouellet})$ & 2.160 & 2.132 & 2.131 & 2.248 & 2.310 & 2.317 & 2.457 & 2.428 \\
\hline
\end{tabular}

Table 4 Bending strength for the 8 studied mixtures of RCC by the models - proportioning $200 \mathrm{~kg} / \mathrm{m}^{3}$.

\begin{tabular}{l|c|c|c|c|c|c|c|c}
\hline Mixture & M1 & M2 & M3 & M4 & M5 & M6 & M7 & M8 \\
\hline \hline Compressive strength of the $\mathrm{RCC} \mathrm{Fc}(\mathrm{MPa})$ & 10.002 & 9.751 & 9.772 & 10.950 & 11.530 & 11.586 & 13.153 & 12.903 \\
\hline Bending strength $\mathrm{F}_{f}(\mathrm{MPa})(\mathrm{ACI})$ & 1.901 & 1.878 & 1.880 & 1.985 & 2.035 & 2.040 & 2.167 & 2.147 \\
\hline Bending strength $\mathrm{F}_{f}(\mathrm{MPa})(\mathrm{Ouellet})$ & 2.878 & 2.844 & 2.847 & 3 & 3.072 & 3.078 & 3.263 & 3.234 \\
\hline
\end{tabular}


Table 5 Bending strength for the 8 studied mixtures of RCC by the models - proportioning $250 \mathrm{~kg} / \mathrm{m}^{3}$.

\begin{tabular}{|c|c|c|c|c|c|c|c|c|}
\hline Cement proportioning $250 \mathrm{~kg} \quad$ Mixture & M1 & M2 & M3 & M4 & M5 & M6 & M7 & M8 \\
\hline Compressive strength of the RCC Fc (MPa) & 15.742 & 15.389 & 15.462 & 17.284 & 18.077 & 18.136 & 20.566 & 20.298 \\
\hline Bending strength $\mathrm{F}_{f}(\mathrm{MPa})(\mathrm{ACI})$ & 2.381 & 2.354 & 2.359 & 2.494 & 2.551 & 2.555 & 2.721 & 2.703 \\
\hline Bending strength $\mathrm{F}_{f}(\mathrm{MPa})$ (Ouellet) & 3.544 & 3.507 & 3.515 & 3.699 & 3.776 & 3.782 & 4.006 & 3.982 \\
\hline
\end{tabular}

were presented in Tables 3, 4, and 5.

The experimental results of the present work were reported on

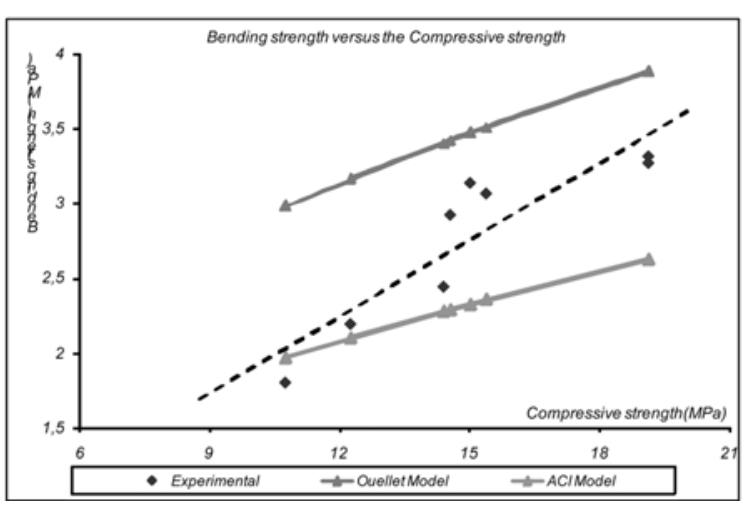

Fig. 3 Relation bending strengths/compressive strengths: empirical and experimental curve - case of proportioning $250 \mathrm{~kg} / \mathrm{m}^{3}$.

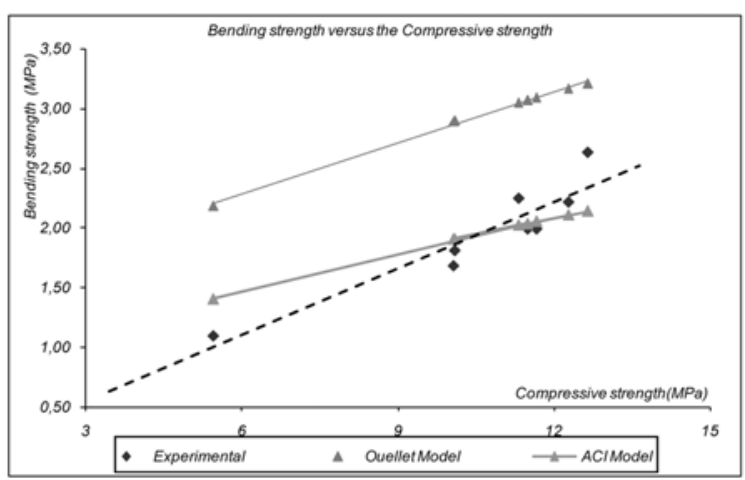

Fig. 4 Relation bending strengths/compressive strengths: empirical and experimental curve - case of proportioning $200 \mathrm{~kg} / \mathrm{m}^{3}$.

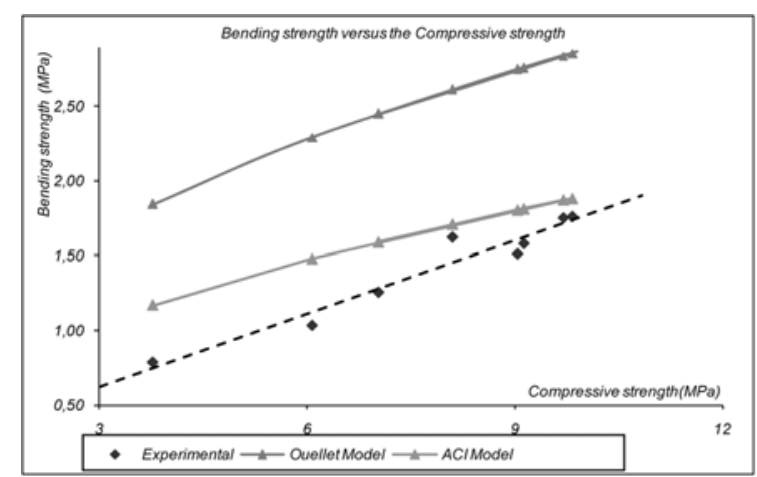

Fig. 5 Relation bending strengths/compressive strengths: empirical and experimental curve - case of proportioning $150 \mathrm{~kg} / \mathrm{m}^{3}$.
Figs. 3, 4, and 5. The obtained variation of bending strength versus compressive strength of the RCC mixtures (Figs. 3, 4, and 5) can be assimilated by the power law described through Eq. (3). This law differs from the laws suggested by Ouellet and ACI and this is because of the aggregates specificity proving the unsuitability of the application of these laws for these kinds of mixtures.

$$
F_{f}=0.24 \times F_{c}^{0.91}
$$

\subsubsection{Interpretations}

Through the present work, the following interpretations are deduced:

- The empirical prediction gives a conventional indication of the bending strengths.

- The strength variation depends specially on the maximum diameter, the water proportioning and the mixtures compactness.

- The values obtained by Ouellet model for the prediction of bending strength, were higher than those calculated by ACI model (Tables 3, 4, and 5).

- The experimental bending strengths obtained on RCC specimens varied between 1.8 MPa for mixture M8 and 3.31 MPa for mixture M6. These results confirmed the improved performances of the RCC as a high compactness material.

- The proportionality was also found between compressive strength and bending strength for the RCC mixtures. Indeed, mixtures giving the higher compressive strengths had also the powerful bending strengths.

- Generally, the ratio between bending strength and compressive strength for the $\mathrm{CC}$ was about 0.10 . For the present case of RCC mixtures, this strengths ratio varied between 0.16 and 0.20 . Marchand et al. ${ }^{1}$ showed that this ratio was rather about 0.12 to 0.15 .

\section{Failure modes}

The failure of specimens under the effect of a bending strength applied in the mid-span of prismatic specimen appeared brutally and by effect of tensile of the bottom fibers which were in traction. This phenomenon is explained by the low tensile strength of RCC mixtures on the tended bottom fibers (Fig. 6) compared to the applied strength. Indeed, granular compactness is opposed to the propagation cracking which will require a higher energy to be propagated.

\section{Conclusions}

The present work comprises experimental measurements and predictions of RCC bending strengths through empirical models which were proposed for conventional concrete (CC) mixtures. 


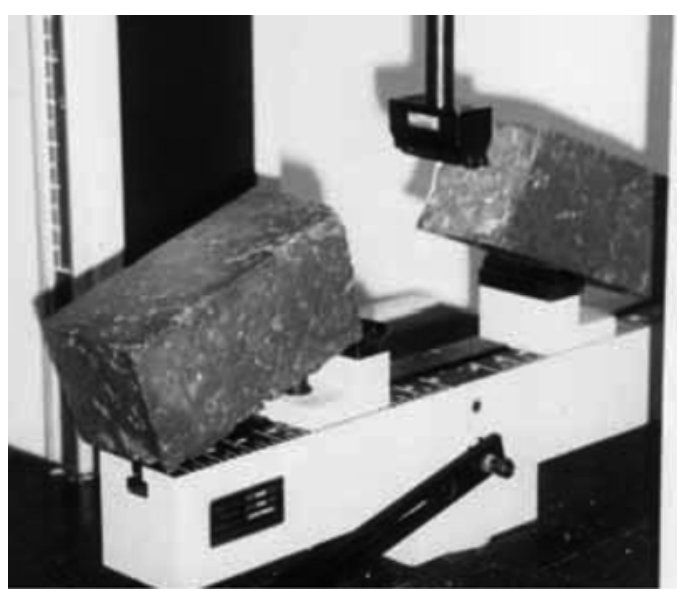

Fig. 6 Failure mode of the prismatic specimens in bending.

The following conclusions are drawn:

1) The prediction of bending strength was made by models which did not give results very converging with those given by the experimental tests.

2) Model, which follows the power law, was proposed for the prediction of bending strength. It is adapted better to the studied mixtures in this work and led to the estimation of bending strength through compressive strength.

3) The high bending strengths of RCC mixture, experimentally measured, can be also identified by the proposed model. This model was concluded suitable for the prediction of bending strength.

4) At equal bending strength, RCC mixtures required a cement quantity lower than that usually used for the formulation of $\mathrm{CC}$ mixtures. It was obtained by the high compactness of the granular skeleton through compaction.

5) The bending strengths of RCC mixture were related to the material compactness obtained by compaction, the cement proportioning and the aggregates kind. Theses parameters produced a cement matrix highly compacted giving an RCC with high mechanicals characteristics.

\section{References}

1. Marchand, J., Gagne, R., Ouellet, E., and Lepage, S., Mixture Proportioning of Roller Compacted Concrete, A Review, Concrete Technology Special Publication SP 171-22, 1997, pp. 457 487.

2. Gauthier, P., Marchand, J., Boisvert, L., Ouellet, E., and Pigeon, M., Conception, Formulation, Production et Mise en Oeuvre de Revêtement en Béton Compacté au Rouleau, Centre de Recherche Interuniversitaire sur le Béton CRIB, Département de Génie Civil, Université Laval, Canada, 2000.

3. Ouellet, E., Marchand, J., and Reid, E., Comportement Mécanique et Durabilité au Gel de Mélanges de Béton Compacté au Rouleau ACI, Section Quebec et de l'est de l'Ontario, Canada, 1998.

4. ACI, Building Code Requirements for Structural Concrete, ACI 318-05 and ACI 318R-05, Detroit, Michigan USA, 2005.

5. Projet National BaCaRa 1988-1996, Le Béton Compacté au Rouleau, Presse ENPC, Paris, 1996, pp. 3 79.

6. Zdiri, M., Ben Ouezdou, M., and Neji, J., Theoretical and Experimental Study of Roller Compacted Concrete Strength, Magazine of Concrete Research MCR, DOI: 10.1680/macr.2007. 00002, Vol. 60, No. 7, 2008, pp. 469 474.

7. EN 12390-5, Essai Pour Beton Durci - Partie 5 : Résistance a la Flexion sur éprouvettes, AFNOR, Oct. 2001.

8. ASTM C 293-02, Standard Test Method for Flexural Strength of Concrete (Using Simple Beam with Center-Point Loading), USA, 2002.

9. De Larrard F., Concrete Mixture Proportioning - A Scientific Approach, Modern Concrete Technologie, Series 9, Mindess S. and A. Bentur, Editors, E \& FN SPON, London, UK, 1999.

10. Sedran T. et De Larrard F., Manuel D'utilisation de Rene$L C P C$, Logiciel d'Optimisation Granulaire, Version 6.1d. http:/ /www.lcpc.fr/fr/presentation/organigramme/divtgce/result, accede Avril 2005.

11. Neville A. M., Propriétés des Bétons, Centre de Recherche Interuniversitaire sur le Beton CRIB, Sherbrooke, Laval, Ed. Eyrolles, France, 2000, pp. 255 401. 